\title{
Moyamoya disease with hemorrhagic stroke in a Nepalese woman
}

\author{
Prabhat Jha $M S^{1}$, Binit Kumar Jha $M S^{2}$, Rajiv Jha $M C h^{3}$, Prakash Bista $M C h^{4}$ \\ 1,2,3,4 National Neurosurgical Referral Center, National Academy of Medical Sciences, Kathmandu, Nepal
}

Date of submission: $24^{\text {th }}$ May 2020

Date of acceptance: $13^{\text {th }}$ July 2020

Date of publication: $12^{\text {th }}$ August 2020

\begin{abstract}
The authors report a case of Moyamoya disease in a middle-aged Nepali female. Though the disease is common in other parts of Asia only one case has been reported previously from Nepal. It should be suspected as a rare cause for spontaneous intracerebral hemorrhage in adults.
\end{abstract}

Key words: Intracerebral hemorrhage, Moyamoya disease

\section{Introduction}

$\mathrm{M}$ oyamoya disease was first described in 1957 as "hypoplasia of the bilateral internal carotid arteries"" Moyamoya means "a puff of smoke" in Japanese which is the characteristic appearance of abnormally dilated vessels seen on angiography. ${ }^{2}$ Though initially described in Japan, it has now been reported from different regions of world in people of different ethnic backgrounds. ${ }^{3}$

The disease can occur in children $<5$ years of age or in adults in their mid-40s. ${ }^{4}$ Hemorrhagic manifestations are more common in adults and ischemic manifestations are more common in children and depends on the region of the brain involved. ${ }^{5}$ The pathophysiology involves hyperplasia of smooth muscle cells and luminal

Access this article online
Website: https://www.nepjol.info/index.php/NJN
DOI: https://doi.org/10.3126/njn.v17i2.30179
HOW TO CITE
Jha P, Jha BK, Jha R, Bista P. Moyamoya disease with hemorrhagic
stroke in a Nepalese woman. NJNS. 2020;17(2):69-72
${ }^{1}$ ORCID id: 0000-0001-5504-5917
${ }^{2}$ ORCID id: 0000-0002-0844-2538
${ }^{3}$ ORCID id: 0000-0002-2830-7835
${ }^{4}$ ORCID id: 0000-0002-4811-6964
Address for correspondence:
Dr. Prabhat Jha
National Neurosurgical Referral Center
National Academy of Medical Sciences
Contact number: $977-9851208714$
E-mail: prabhatkaushaljha@gmail.com
Copyright $\odot 2020$ Nepalese Society of Neurosurgeons (NESON)
ISSN: 1813-1948 (Print), 1813-1956 (Online)

cc (i) (2) This work is licensed under a Creative Commons Attribution-Non Commercial 4.0 International License. thrombosis with media attenuation and internal elastic lamina breakdown. ${ }^{6}$

Gold standard for diagnosis is angiography which shows the attenuated internal carotid arteries along with its branches and the collaterals. Disease severity can be classified based upon the Suzuki grading system. ${ }^{2}$ Treatment can be medical with antiplatelet agents and calcium channel blockers ${ }^{7}$ or surgical. The surgical management involves placing either an artery or a vascularized tissue directly or the surface of the brain or anastomosing a branch of external carotid artery with a branch of internal carotid artery. ${ }^{8}$

\section{Case presentation}

A 49 years old female from Kathmandu was admitted with complaints of severe headache for 1 day which started at around 6 am while she was taking a bath. The headache was severe, global and associated with vomiting two episodes containing food particles. The patient developed weakness on the left side of her body. There was no history of fever, headache, trauma, loss of consciousness, abnormal body movement. She is a known case of hypertension not under medication. She is a regular smoker and alcohol consumer.

At the time of admission her pulse was $78 / \mathrm{min}$, respiratory rate $17 / \mathrm{min}$, blood pressure $160 / 90 \mathrm{mmHg}$. Glasgow Coma Scale (GCS) was a spontaneous eye opening, oriented and obeying command. Pupils were bilaterally equal reactive to light. Patient had weakness of the left upper and lower limbs with power 3/5 across all major joints. Meningeal and cerebellar signs were absent. Chest, cardiovascular and abdominal examination were within normal limits.

On baseline investigations hemoglobin was $12.9 \mathrm{gm} /$ $\mathrm{dL}$, Total leukocyte count $13500 / \mathrm{mm}^{3}$ with neutrophil $85 \%$ and lymphocyte $22 \%$, platelet $264000 / \mathrm{mm}^{3}$, random 


\section{Jha et al}

blood sugar $138 \mathrm{mg} / \mathrm{dl}$, urea $18 \mathrm{mg} / \mathrm{dl}$, creatinine- $0.6 \mathrm{mg}$ / dl, sodium $136 \mathrm{mEq} / \mathrm{L}$ and potassium $3.1 \mathrm{mEq} / \mathrm{L}$.

Computed tomography (CT) head was acquired which showed right basal ganglia bleed with extension into the lateral ventricle, third ventricle and fourth ventricle. (Figure 1)

Computed tomography angiography (CTA) head was done which showed absent intracranial portions of bilateral internal carotid artery with diffuse network of vessels most likely neovascularization. (Figure 2)

Patient was subjected to digital subtraction angiography (DSA). Right femoral artery was punctured and cannulation of the common carotid artery, internal carotid artery and vertebral artery was done on both sides. Angiogram demonstrated the complete stenotic occlusion of the right distal internal carotid artery with multiple thin collateral vessels giving the impression of puff of smoke appearance. Right middle and anterior cerebral arteries

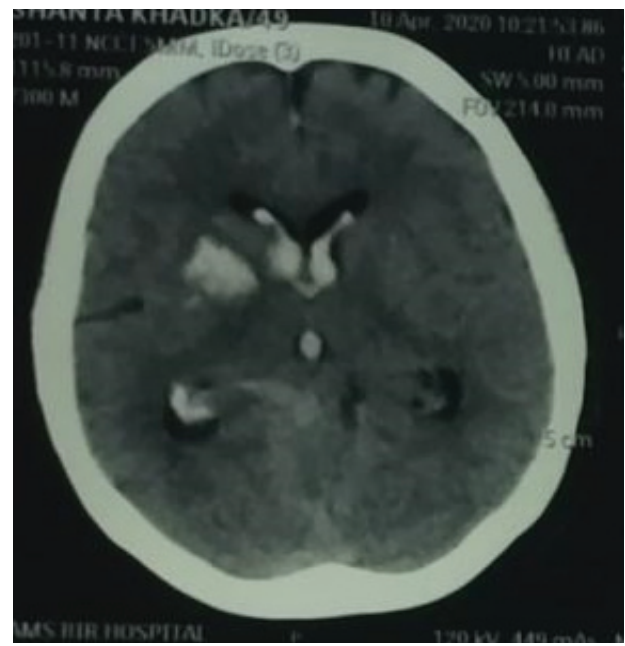

Figure 1: NCCT head showing right basal ganglia bleed with intraventricular extension were not visualized. Left Internal carotid artery was grossly thinned from origin with few collaterals seen from the middle meningeal artery bilaterally. No evidence of thrombus, rupture, aneurysm or fistula was seen. Bilateral vertebral arteries, bilateral posterior cerebral arteries and basilar artery were normal with no evidence of filling defect. Features were consistent with moyamoya disease Suzuki classification grade III on the right side and grade II on the left side. (Figure 3)

She was managed in the intensive care unit with continuous monitoring. Her headache and the weakness on the left side of her body gradually improved. Because of the improvement of her symptoms on conservative management, she wasn't planned for immediate surgery. The patient was also given calcium channel blockernimodipine for 21 days. She was discharged on aspirin and analgesics. On follow up she is doing well. The patient is planned for a superficial temporal artery to middle cerebral artery bypass if she deteriorates.

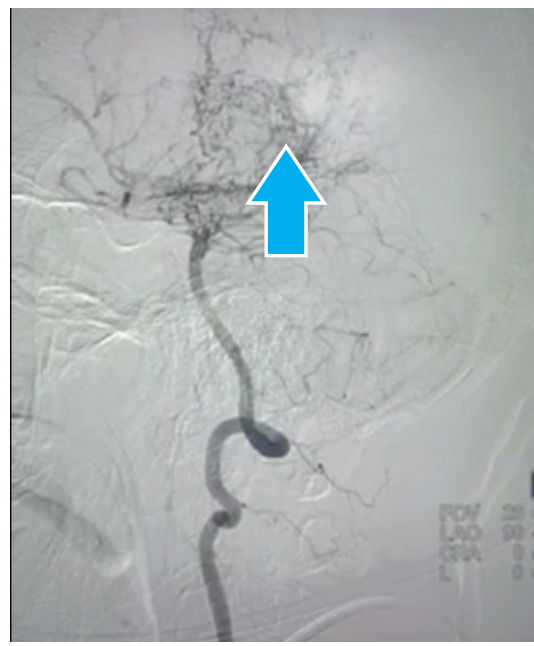

Figure 3: Digital Subtraction Angiography image showing absent anterior and middle cerebral artery replaced by multiple small network of vessels showing puff of smoke appearance.

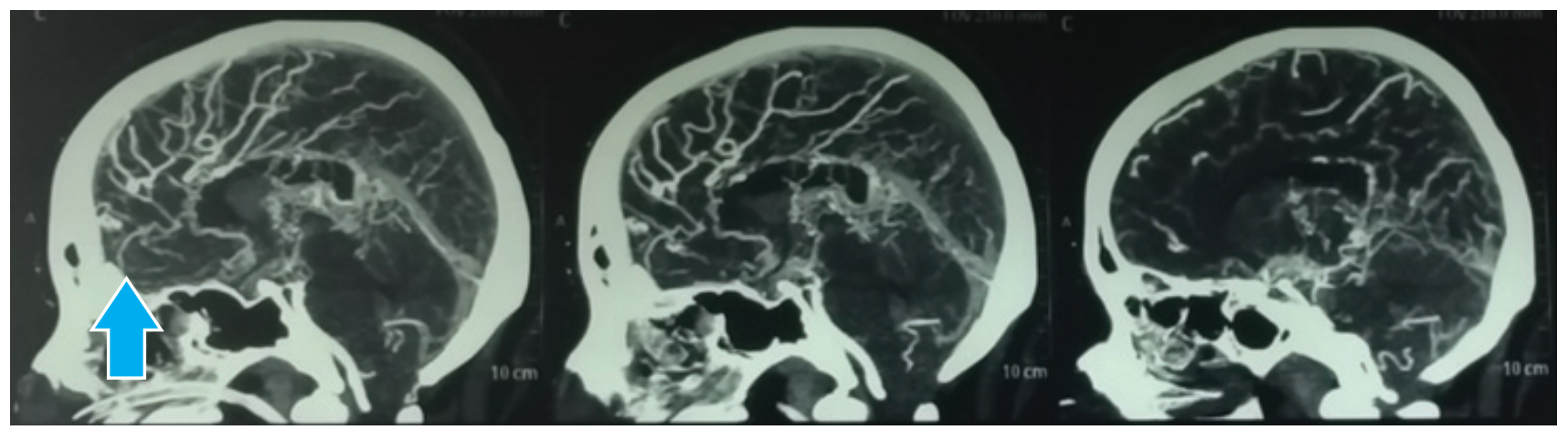

Figure 2: CT Angiography of head showing absent intracranial portions of bilateral internal carotid artery with diffuse network of vessels most likely neovascularization 


\section{Discussion}

Moya moya disease is a condition initially reported in Japan and is a cause of stroke in both the pediatric population and in adults. ${ }^{9}$ Very few cases have been previously reported from Nepal. ${ }^{10}$ The exact reason why this disease is not common in Nepal is not known though in countries like Japan genetic predisposition has been suggested with approximately $10 \%$ of cases transmitted in autosomal recessive fashion. It is one of the rare causes of cerebrovascular emergencies. ${ }^{10}$ Adults usually present with intracerebral hemorrhage as in our case. ${ }^{5}$

Moyamoya disease has different manifestations, stroke (ischemic stroke is more common in children and hemorrhagic stroke commoner in adults), seizure disorder, and choreiform movements. ${ }^{11}$ Our patient presented with a headache, vomiting and weakness of the right side of the body. CT head showed the right basal ganglia bleed. Bleeding occurs due to rupture of fragile collateral vessels associated with moyamoya as progressive stenosis of the internal carotid artery occurs. ${ }^{12}$

The clinical diagnosis is usually confirmed using conventional angiography or CT /MR angiography showing the typical vascular appearance. ${ }^{13,14}$ Our patient underwent both CT angiography and conventional angiography which were diagnostic. The classical moyamoya appearance as seen in our patient occurs due to stenosis of the intracranial portion of the internal carotid artery. Our patient was graded using the Suzuki system. ${ }^{2}$ The pathognomonic arteriographic findings bilateral though the severity can differ between sides. Even when the patient presents with unilateral findings, bilateral disease eventually develops in $40 \%$. ${ }^{15}$ Our patient had more severe disease on the left side, Suzuki grade III than on right side, Suzuki grade II.

The treatment of patients presenting with acute features involves admission in a high dependency unit, normalization of oxygenation, blood sugar, regular monitoring of Glasgow Coma Scale. ${ }^{16}$ Surgical management in adults involves direct revascularization by superficial temporal artery to middle cerebral artery bypass. In children indirect revascularization techniques such as encephalomyosynangiosis (implanting temporalis muscle on brain surface) or encephaloduroarteriosynangiosis (dissected superficial temporal artery is laid on cortical surface) are preferred. ${ }^{14}$

A large survey from Japan showed no significant differences in outcome between medically and surgically treated patients with moyamoya, although a more recent review revealed that $38 \%$ of 651 patients with moyamoya who were initially treated medically ultimately underwent surgery because of progressive symptoms. ${ }^{17}$ Our patient improved after admission to hospital and was given the options for both medical and surgical management. She decided to be on medical treatment and is planned for vascular bypass surgery if needed.

\section{Conclusion}

Though Moyamoya disease is extremely rare in Nepal and only few cases have been previously reported it can be an uncommon cause of intracerebral bleeding. It can be diagnosed based upon the characteristic angiographic findings.

\section{Acknowledgement}

The authors would like to thank the patient and patient party who stood tough and gave permission for the publication of this case report.

Conflict of Interest: None

Source(s) of support: None

\section{References}

1. Takeuchi K, Shimizu K. Hypoplasia of the bilateral internal carotid arteries. Brain Nerve 1957;9:37-43.

2. Suzuki J, Takaku A. Cerebrovascular "moyamoya" disease. Disease showing abnormal netlike vessels in base of brain. Arch Neurol. 1969;20(3):288-99. https://doi.org/10.1001/ archneur.1969.00480090076012

3. Suzuki J, Kodama N. Moyamoya disease-a review. Stroke. 1983;14(1):104-9. https://doi. org/10.1161/01.str.14.1.104

4. Baba T, Houkin K, Kuroda S. Novel epidemiological features of moyamoya disease. J Neurol Neurosurg Psychiatry. 2008;79(8):900-4. https://doi. org/10.1136/jnnp.2007.1306665.

5. Han DH, Kwon OK, Byun BJ, et al. A co-operative study: clinical characteristics of 334 Korean patients with moyamoya disease treated at neurosurgical institutes (1976-1994). The Korean Society for Cerebrovascular Disease. Acta Neurochir (Wien). 2000;142(11):1263-74. https://doi.org/10.1007/ s007010070024

6. Takagi Y, Kikuta K, Nozaki K, Hashimoto N. Histological features of middle cerebral arteries from patients treated for Moyamoya disease. Neurol Med Chir (Tokyo). 2007;47(1):1-4. https://doi. org/10.2176/nmc.47.1

7. Ikezaki K. Rational approach to treatment of moyamoya disease in childhood. J Child 
Neurol. 2000;15(5):350-6. https://doi. org/10.1177/088307380001500512

8. Smith ER, Scott RM. Surgical management of moyamoya syndrome. Skull Base. 2005;15(1):15-26. https://doi.org/10.1055/s-2005-868160

9. Wakai K, Tamakoshi A, Ikezaki K, et al. Epidemiological features of moyamoya disease in Japan: findings from a nationwide survey. Clin Neurol Neurosurg. 1997;99 Suppl 2:S1-S5. https:// doi.org/10.1016/s0303-8467(97)00031-0

10. Paudel R, Chettri PK, Thapa LJ, Tayal A, Rana PVS, Devkota UP. Moyamoya disease presenting with hemiballismus and parkinsonism. Neurology Asia. 2011; 16(2):171-3.

11. Fukui M. Current state of study on moyamoya disease in Japan. Surg Neurol. 1997;47(2):138-143. https:// doi.org/10.1016/s0090-3019(96)00358-8

12. Iwama T, Morimoto M, Hashimoto N, Goto Y, Todaka T, Sawada M. Mechanism of intracranial rebleeding in moyamoya disease. Clin Neurol Neurosurg. 1997;99:Suppl 2:S187-S190.

13. Fukui M. Guidelines for the diagnosis and treatment of spontaneous occlusion of the circle of Willis ('moyamoya' disease). Research Committee on
Spontaneous Occlusion of the Circle of Willis (Moyamoya Disease) of the Ministry of Health and Welfare, Japan. Clin Neurol Neurosurg. 1997;99 Suppl 2:S238-S240.

14. Fukui M. Guidelines for the diagnosis and treatment of spontaneous occlusion of the circle of Willis ('moyamoya' disease). Research Committee on Spontaneous Occlusion of the Circle of Willis (Moyamoya Disease) of the Ministry of Health and Welfare, Japan. Clin Neurol Neurosurg. 1997;99 Suppl 2:S238-S240.

15. Kelly ME, Bell-Stephens TE, Marks MP, Do HM, Steinberg GK. Progression of unilateral moyamoya disease:Aclinical series. CerebrovascDis. 2006;22(23):109-15. https://doi.org/10.1159/000093238

16. Fujiwara J, Nakahara S, Enomoto T, Nakata Y, Takita $\mathrm{H}$. The effectiveness of $\mathrm{O} 2$ administration for transient ischemic attacks in moyamoya disease in children. Childs Nerv Syst 1996;12:69-75.

17. Ikezaki K. Rational approach to treatment of moyamoya disease in childhood. $\mathbf{J}$ Child Neurol.2000;15(5):350-6.https://doi. org/10.1177/088307380001500512 